\title{
Sports Medicine: Issues, Challenges, Controversies, Opportunities and Responsibilities
}

\section{Senthil P Kumar ${ }^{1 *}$ and Anup Kumar ${ }^{2}$}

${ }^{1}$ Department of Physiotherapy, Kasturba Medical College, Manipal University, Mangalore, India

${ }^{2}$ Department of Orthopaedics, Kasturba Medical College, Manipal University, Mangalore, India

\begin{abstract}
Sports medicine is a field in itself, evolving through a long period of practice, education, research and administration, not only in sports but also to exercise and physical activity in health and disease. The objective of this editorial is to provide a broader perspective of Sports Medicine, its issues, challenges and controversies in the past and present, with opportunities and responsibilities for the future.
\end{abstract}

Keywords: Sports medicine; Exercise physiology; Professionalization

\section{Introduction}

Sports medicine is a field in itself, evolving through a long period of practice, education, research and administration, not only in sports but also to exercise and physical activity in health and disease [1]. Sports medicine is recognized as a multidisciplinary interprofessional collaborative knowledge-translation approach and has its own influences ranging from an individual's own performance or health status to a national team's victory or public health status [2]. The objective of this editorial is to provide a broader perspective of Sports Medicine, its issues, challenges and controversies in the past and present, with opportunities and responsibilities for the future.

\section{Issues in sports medicine-individual or environmental?}

Analogous with the intrinsic and extrinsic risk factors for any sports injury; individual and environmental factors interact in a complex manner thus generating multifaceted issues which can be addressed easily from a biopsychosocial perspective [3]. Biological issues are often addressed under the biomedical domain (neuromusculoskeletal injuries, sudden cardiac death, hypertension, concussion, methicillinresistant Staphylococcus aureus infections, the female athlete triad, diabetes mellitus, and asthma) [4] whilst the psychological factors arise out of mental aspects of an individual that include but not limited to psychiatric [5], psychological (Fears about reinjury, fears related to surgery, and lack of patience with recovery/rehabilitation) [6] and neuropsychological issues [5], and social issues include administrative (program management- choosing program director, physician-coach inter-relationship) [7], ethical (autonomy, paternalism, truthfulness, professional loyalty) [8], medico-legal (potentially fatal medical conditions such as knee dislocation, cervical spine trauma, cardiac abnormalities, heat illness, and concussion [9], and physicians may be held legally liable for not doing a standardized pre-participation evaluation, for not administering adequate on-site or after injury care, or for violating an individual's civil rights by refusing to allow continued participation because of medical risk) [10], playing fieldrelated(artificial turf versus natural grass) [11], sports-related(martial arts) [12], and profession/work-related(dancers [13], musicians [14]) or recreation-related (addictive disorders such as gambling in athletes) [15].

\section{Challenges and controversies in sports medicine-sport- specific or injury-specific?}

Differences and variations are inherent manifestations of 'uniqueness' in all types of sports and thus "where there are issues, there are controversies" both sport-specific and injury-specific. Some of the few widely reported controversies in sports medicine were on concussion in young athlete (return-to-sport decisions) [16], conflict of interest (pharmaceutical and device manufacturing companies and financial sponsors) [17], and core stabilization as a treatment for low back pain (technique, patient selection, dose-response, and long-term outcome) [18], femoroacetabular impingement (diagnostic criteria, natural history and role of surgery) [19], and spondylolysis in adolescent athletes (diagnostic imaging modalities and use of bracing) [20], stingers (associated injuries, recurrence, return-to-sport decisions) [21], and sudden cardiac death in young athletes (preparticipation physical examination, emergency responses and secondary preventive strategies) [22].

\section{Opportunities and responsibilities in sports medicine-what or who?}

"Research seeded by questions and hypotheses has its own roots of sports medicine knowledge watered by issues and controversies to bear fruits of opportunities on branches of responsibilities."

Traditionally, sports medicine was perceived as a career opportunity [23] per se more than what is in it. There is plenty of growing opportunity for research in sports medicine considering the limited evidence on aforementioned topics. The future holds bright for use of bioactive factors [24], genetic research [25], allografts [26] and computer-assisted surgery [27], whilst professionalizing into primary care [28] and pediatric sports medicine [29].

It is not only a joint responsibility when it comes to real-life sports medicine scenario on person, professionals and stake-holders, but also the scientific arena on researchers, reviewers and editors to ensure adequate unbiased disclosure of facts and findings, and JSMDS welcomes papers on such aspects in the field of sports medicine and is also committed equally in publishing negative results' studies

\section{References}

1. Pate RR, Pratt M, Blair SN, Haskell WL, Macera CA, et al (1995) Physical activity and public health. A recommendation from the Centers for Disease

*Corresponding author: Senthil P Kumar, Associate professor, Department of Physiotherapy, Kasturba Medical College, Manipal University, Mangalore, India Tel: +919341963889; E-mail: senthil.kumar@manipal.edu

Received June 30, 2012; Accepted July 02, 2012; Published July 03, 2012

Citation: Kumar SP and Kumar A (2012) Sports Medicine: Issues, Challenges, Controversies, Opportunities and Responsibilities. J Sports Med Doping Stud 2:e119. doi:10.4172/2161-0673.1000e119

Copyright: (c) 2012 Kumar SP, et al. This is an open-access article distributed under the terms of the Creative Commons Attribution License, which permits unrestricted use, distribution, and reproduction in any medium, provided the original author and source are credited. 
Citation: Kumar SP and Kumar A (2012) Sports Medicine: Issues, Challenges, Controversies, Opportunities and Responsibilities. J Sports Med Doping Stud 2:e119. doi:10.4172/2161-0673.1000e119

Control and Prevention and the American College of Sports Medicine. JAMA 273: 402-407.

2. Peeler J, Leiter J, MacDonald $P$ (2010) Accuracy and reliability of anterior cruciate ligament clinical examination in a multidisciplinary sports medicine setting. Clin J Sport Med 20: 80-85.

3. Ahern DK, Lohr BA (1997) Psychosocial factors in sports injury rehabilitation Clin Sports Med 16: 755-768.

4. Ting $\mathrm{JH}$, Wallis $\mathrm{DH}(2007)$ Medical management of the athlete: evaluation and treatment of important issues in sports medicine. Clin Podiatr Med Surg 24 127-158

5. Esfandiari A, Broshek DK, Freeman JR (2011) Psychiatric and neuropsychological issues in sports medicine. Clin Sports Med 30: 611-627.

6. Mann BJ, Grana WA, Indelicato PA, O'Neill DF, George SZ (2007) A survey of sports medicine physicians regarding psychological issues in patient-athletes. Am J Sports Med 35: 2140-2147.

7. Rowe DS, Fox KP (1980) Administrative issues in the management of a sports medicine program. Yale J Biol Med 53: 289-294.

8. Sim J (1993) Sports medicine: some ethical issues. Br J Sports Med 27: 95100.

9. Sanders AK, Boggess BR, Koenig SJ, Toth AP (2005) Medicolegal issues in sports medicine. Clin Orthop Relat Res 38-49.

10. Pearsall AW 4th, Kovaleski JE, Madanagopal SG (2005) Medicolegal issues affecting sports medicine practitioners. Clin Orthop Relat Res 50-57.

11. Wright JM, Webner D (2010) Playing field issues in sports medicine. Curr Sports Med Rep 9: 129-133.

12. Nishime RS (2007) Martial arts sports medicine: current issues and competition event coverage. Curr Sports Med Rep 6: 162-169.

13. Toledo SD, Akuthota V, Drake DF, Nadler SF, Chou LH (2004) Sports and performing arts medicine. 6 . Issues relating to dancers. Arch Phys Med Rehabil 85:S75-78.

14. Toledo SD, Nadler SF, Norris RN, Akuthota V, Drake DF, et al. (2004) Sports and performing arts medicine. 5. Issues relating to musicians. Arch Phys Med Rehabil 85: S72-74.

15. Miller TW, Adams JM, Kraus RF, Clayton R, Miller JM, et al (2001) Gambling as an addictive disorder among athletes: clinical issues in sports medicine. Sports Med 31: 145-152.
6. Standaert CJ, Herring SA, Cantu RC (2007) Expert opinion and controversies in sports and musculoskeletal medicine: concussion in the young athlete. Arch Phys Med Rehabil 88: 1077-1079.

17. Standaert CJ, Schofferman JA, Herring SA (2009) Expert opinion and controversies in musculoskeletal and sports medicine: conflict of interest. Arch Phys Med Rehabil 90: 1647-1651.

18. Standaert CJ, Herring SA (2007). Expert opinion and controversies in musculoskeletal and sports medicine: core stabilization as a treatment for low back pain. Arch Phys Med Rehabil 88: 1734-1736.

19. Standaert CJ, Manner PA, Herring SA (2008) Expert opinion and controversies in musculoskeletal and sports medicine: femoroacetabular impingement. Arch Phys Med Rehabil 89: 890-893.

20. Standaert CJ, Herring SA (2007) Expert opinion and controversies in sports and musculoskeletal medicine: the diagnosis and treatment of spondylolysis in adolescent athletes. Arch Phys Med Rehabil 88: 537-540.

21. Standaert CJ, Herring SA (2009) Expert opinion and controversies in musculoskeletal and sports medicine: stingers. Arch Phys Med Rehabil 90: 402-406.

22. Rao AL, Standaert CJ, Drezner JA, Herring SA (2010) Expert opinion and controversies in musculoskeletal and sports medicine: preventing sudden cardiac death in young athletes. Arch Phys Med Rehabil 91: 958-962.

23. Pana AL, McShane J (2001) Gender influences on career opportunities, practice choices, and job satisfaction in a cohort of physicians with certification in sports medicine. Clin J Sport Med 11: 96-102.

24. Angel MJ, Sgaglione NA, Grande DA (2006) Clinical applications of bioactive factors in sports medicine: current concepts and future trends. Sports Med Arthrosc 14:138-145

25. Trent RJ, Yu B (2009) The future of genetic research in exercise science and sports medicine. Med Sport Sci 54: 187-195.

26. Harner CD, Lo MY (2009) Future of allografts in sports medicine. Clin Sports Med 28: 327-340.

27. Koh JL (2008) The future of computer-assisted surgery (CAS) in sports medicine. Sports Med Arthrosc16: 108-110.

28. Matheson GO (2003) An active future for primary care sports medicine. Phys Sportsmed 31: 2

29. Luckstead EF Sr (2002) What is the future potential for pediatric sports medicine? American and international pediatric sport perspectives. Pediatr Clin North Am 49: 857-859. 